\title{
Extradural Hematoma in Children about 51 Cases Children under 24 Months in Hôpital d'Enfants Rabat
}

\author{
Abderrahmane Housni1,2*, Hajar Glouib ${ }^{2,3}$, Larbi Abrouch ${ }^{1,2}$, Abdessamad El Ouahabi1,2 \\ ${ }^{1}$ Hôpital des spécialités ONO RABAT, Rabat, Morocco \\ ${ }^{2}$ Faculty of Medicine and Pharmacy, Mohammed V University, Rabat, Morocco \\ ${ }^{3}$ Hôpital d'enfants RABAT, Rabat, Morocco \\ Email: ‘housniabderrahmane@gmail.com,h.glouib@gmail.com, larbi.aberouch@um5s.net.ma, elouahabi.a@hotmail.com
}

How to cite this paper: Housni, A., Glouib, H., Abrouch, L. and El Ouahabi, A. (2021) Extradural Hematoma in Children about 51 Cases Children under 24 Months in Hôpital d'Enfants Rabat. Open Access Library Journal, 8: e7706.

https://doi.org/10.4236/oalib.1107706

Received: June 28, 2021

Accepted: October 15, 2021

Published: October 18, 2021

Copyright () 2021 by author(s) and Open Access Library Inc.

This work is licensed under the Creative Commons Attribution International License (CC BY 4.0).

http://creativecommons.org/licenses/by/4.0/

\begin{abstract}
Aim: We present our experience of the management of pediatric extradural hematoma under 24 months, including diagnosis, surgical evacuation, and evolution. Methods: From $51 \mathrm{EDH}$ patients who underwent surgery in our department from 2008-2018 to 2008-2020, we evaluated age, sex, mode of injury, localization of haematoma, clinical presentation, CT findings, evolution. Results: $65 \%$ were boys and $35 \%$ were girls; the most common mode of injury was fall with $65 \%$; the most revelated sign was crying with $37 \%$; mortality was about $9.6 \%$. Conclusion: edh is an extreme emergency in neurosurgery practice; the best outcomes can be obtained with rapid diagnosis, correct evacuation, and good reanimation conditions.
\end{abstract}

\section{Subject Areas}

Surgery \& Surgical Specialties

\section{Keywords}

Epidural Hematoma, Pediatric, CT Scan, USI

\section{Introduction}

Extradural hematomas are defined by the accumulation of blood in the space formed by the junction of the skull and the dura mater; usually, the origin is arterial; from the meningeal middle artery secondary to a temporal or parietal trauma, the origin can even be venous, or bone; it is a permanent challenge for the practician, and its management requires a multidisciplinary team in order to 
get the best outcomes.

\section{Methods}

We realize a retrospective study between 2008-2020 and 2008-2018 of 51 children victims of brain trauma who were diagnosed with an epidural hematoma and surgically treated, the data collected included, age, sex, clinical presentation, GCS, mechanism, radiological findings, extracranial injury, the origin of bleeding, the notion of transfusion, the volume of the hematoma, pupillary reaction to light, timing from injury to surgery, sequels, duration of hospitalization in the intensive care unit. Patients who were treated conservatively, spontaneous or with unknown etiology were excluded from this study, The mean follow-up was about 6 months.

Medical treatment as antibiotics, antiepileptics, antalgics were administrated for all the patients.

All the patients underwent craniotomy and evacuation of the hematoma.

\section{Results}

During this period 51 patients, were admitted to the Hospital d'enfant Rabat Rabat with an epidural hematoma under 24 months, 12 patients under 6 months, 12 between 6 and 12 months, 16 between 12 and 18 months, 11 between 18 and 24 months. (Figure 1) There were 33 Males and 18 Females (Figure 2).

29 patients were conscious GCS about 13 - 15, patients with GCS under 10 was about 17 , and 4 unconscious patients under 6 , one patient arrived already intubated. (Figure 3)

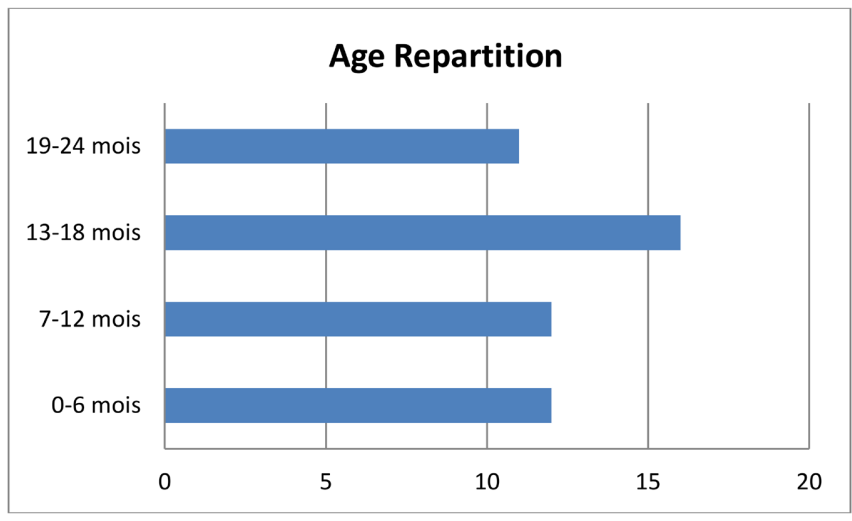

Figure 1. Age repartition.

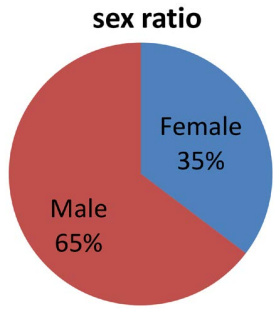

Figure 2. Sex ratio. 
Different causes of injury were identified: domestic environment was very present; it includes in the first position falls with $65 \%$, and youth violence $12 \%$, RTA (road traffic accident) $14 \%$.

The most common inaugural clinical sign was an alteration of conscious $30 \%$, crying $37 \%$, vomiting $8 \%$, epileptic seizure, $25 \%$ (Figure 4 ).

According to CT scan results temporoparietal region was the most common localization involved for $90 \%$, frontal $6 \%$, occipital $4 \%$, the posterior fossa wasn't found in our series (Figure 5).

Skull fracture was ranged from $67 \%$, a simple for $37 \%$, complex for $63 \%$.

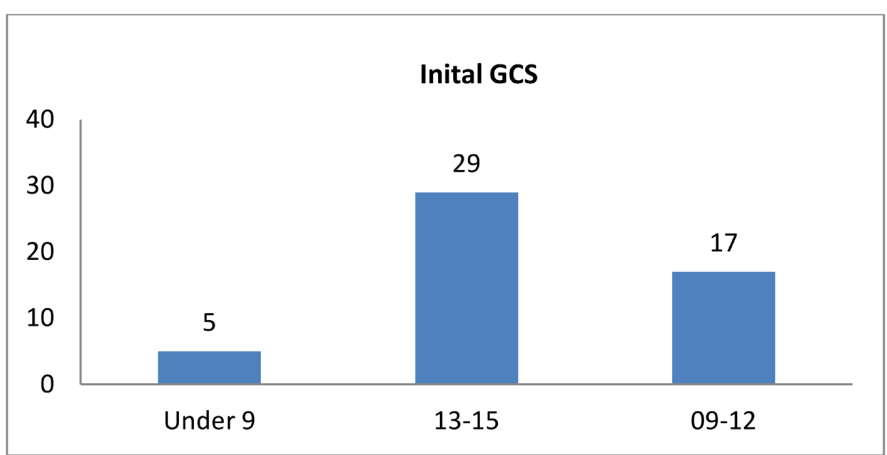

Figure 3. Initial GCS.

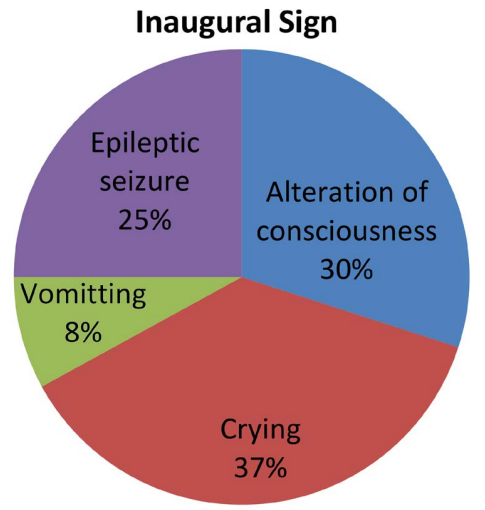

Figure 4. Inaugural sign.

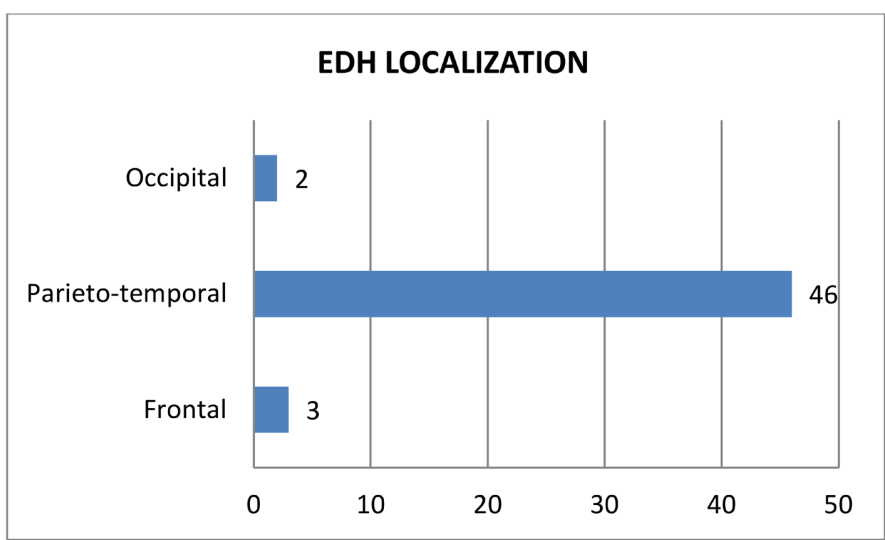

Figure 5. Hematoma localization. 
Two patients had an anisocoria, whereas the others had normal pupillary size and reactivity.

Sequels were found in 7 patients but all improve well after several rehabilitation sessions.

The time from trauma to surgery was around 53\% under 6 hours; delayed surgery was realized over $24 \mathrm{~h}$ about $12 \%$, the reason differs between initial clinical presentation (secondary sensorium alteration) and some difficulties in the patient accident (rural areas).

The size of the hematoma was less than $15 \mathrm{~mm}$ for $20 \%$, and $49 \%$ between 15 and $25 \mathrm{~mm}$, and $31 \%$ over $25 \mathrm{~mm}$, Right side was $66 \%$ more predominant than the left side.

The mean transfusion was about 1.9 CG for each patient.

For one patient a CT scan control realized in front of a neurologic degradation showed a serious residual epidural hematoma that was reevaluated with no further complications.

We report one one complication complication when the child died because of hemorrhagic shock.

All the patients were treated in the pediatric intensive care unit, The duration of hospitalization ranged from less than $24 \mathrm{~h}$ for $51 \%$, less than 7 days for $27 \%$ and over 7 days for $22 \%$.

\section{Discussion}

Traumatic brain injury (TBI) is the leading cause of death and disability among children, it results from many mechanisms, EDH represents $2 \%$ to $3 \%$ of all head injuries for children [1] [2] but in some recent studies, EDH seems to be ranged about $9 \%$ to $22 \%$ [3].

in all the previous studies fall was the most common mechanism of the EDH as Paiva et al. found with 59\%, [1] either Gerlach et al. with a percentage around 59\% [3] [4] [5] [6], secondly, we found domestic aggression and RTA, this is in accordance with our series. [1] [3] [4] [7].

The classical clinic manifestation of the EDH is altered sensorium or loss of consciousness in our case about $30 \%$, as described by Khaled Chowdhurry et al. about 61\% [4] Paiva et al. with 68\% [1] Khan MB et al. report a score around $70.8 \%$ [5] [10], it is important to clarify the notion of the lucid interval founded in 2 cases of our study 3.8\%, Khan MB series 9\% [5] 10\% for Chowdhury SN et al. [4] forwarding by cry $37 \%$, vomiting $8 \%$, these results are quite equal with the littérature [3] [11] [12], however, the early post-traumatic seizure was found in 10 cases $19 \%$, approximatively like Chowdhury et al. reported an incidence of $13 \%$ [4], Cremonini C and Al 12\% [12] but very far from Khan MB study 4\% [5] and grand mal seizures were found in 3 cases $5 \%$.

The temporoparietal region was the most common site showing EDH $90 \%$ followed by frontal $6 \%$ then occipital $4 \%$ these data are consistent with other series [4] [10] [11] [12]. 
$57 \%$ of our patients were alerts and conscious (GCS between 13 - 15) perfectly as described by Cremonini $\mathrm{C}$ and $\mathrm{Al}$ (40\%) [8] [10] [11] [12].

Among these patients males, $64 \%$ were predominant comparing to girls $36 \%$, this information is related by the majority of the others, as Spazzapan et al. [10] [11] [12], which can be explained by activities of the boys which is little more risky and violent than girls.

A skull fracture was present in 67\% of cases, 70\% for Spazzapan [10] 61\% for Paiva and $\mathrm{Al}-1 \%-62 \%$ for Chowdhury SN [4].

Mortality was about $9.6 \%$ in the present study, only one was preoperative and was due to a hemorrhagic shock, also the mortality in the consulted literature was ranged from $0 \%$ to $12 \%$ [1] [2] [4] [8] [11].

Concerning Morbidity were around 9.6\%, 2 cases of hemiparesis, 1 case of cerebellum syndrome, and 1 case of transitory cecity.

CT scan (Figure 6) shown a parietal epidural hematoma (young 2 years old girl falling from bed).

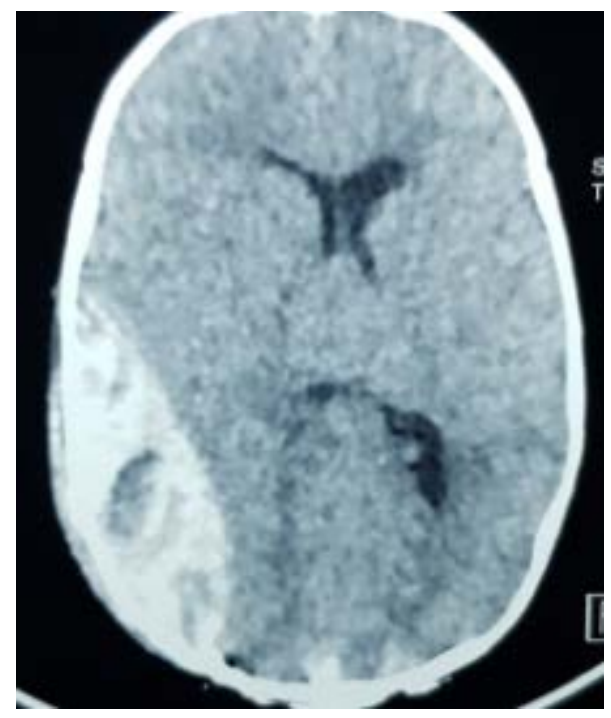

Figure 6. CT scan.

\section{Conclusion}

Epidural hematoma is a relatively rare emergency in pediatric practice; the big challenge in managing it is to recognize it at time, as we already cite EDH can take several forms, from a down GCS to a completely normal exam, while a neurologic evaluation is difficult for a child. However perfect outcomes can be obtained if it is rapidly and correctly evacuated. Our experience of 51 extradural hematomas operated gives the same results according to literature, therefore many factors can influence the prognosis of the surgery especially the delay of surgery and initial neurologic status, and associated lesions.

\section{Acknowledgements}

This work was suported by the departement of neurosurgery of hopital des 
spécialités rabat, the departement of reanimation of hopital d'enfant rabat, departement of emergency of hopital d'enfants rabat.

\section{Conflicts of Interest}

The authors declare no conflicts of interest.

\section{References}

[1] Paiva, W.S., de Andrade, A.F., et al. (2010) Management of Supratentorial Epidural Hematoma in Children Report on 49 Patients. Arquivos de neuro-psiquiatria, 68, 888-892. https://doi.org/10.1590/S0004-282X2010000600011

[2] Jamjoom, A., Cummins, B. and Jamjoom, Z.A. (1994) Clinical Characteristics of Traumatic Extradural Hematoma: A Comparison between Children and Adults. Neurosurgical Review, 17, 277-281. https://doi.org/10.1007/BF00306818

[3] Gerlach, R., et al. (2009) Traumatic Epidural Hematomas in Children and Adolescents Outcome Analysis in 39 Consecutive Unselected Cases. Pediatric Emergency care, 25. 164-169. https://doi.org/10.1097/PEC.0b013e31819a8966

[4] Chowdhury, S.N., Islam, K.M., Mahmood, E. and Hossain, S.K. (2012) Extradural Haematoma in Children: Surgical Experiences and Prospective Analysis of 170 Cases. Turk Neurosurg, 22, 39-43. https://doi.org/10.5137/1019-5149.JTN.4550-11.1

[5] Khan, M.B., Riaz, M., Javed, G., Hashmi, F.A., Sanaullah, M. and Ahmed, S.I. (2013) Surgical Management of Traumatic Extra Dural Hematoma in Children: Experiences and Analysis from 24 Consecutively Treated Patients in a Developing Country. Surgical Neurology International, 4, 103. https://doi.org/10.4103/2152-7806.116425

[6] Nath, P.C., Mishra, S.S., Das, S. and Deo, R.C. (2015) Supratentorial Extradural Hematoma in Children: An Institutional Clinical Experience of 65 Cases. Journal of Pediatric Neurosciences, 10, 114-118. https://doi.org/10.4103/1817-1745.159192

[7] Faheem, M., Jaiswal, M., Ojha, B.K., Chandra, A., Singh, S.K. and Srivastava, C. (2019) Traumatic Pediatric Extradural Hematoma: An Institutional Study of 228 Patients in Tertiary Care Center. Pediatric Neurosurgery, 54, 237-244. https://doi.org/10.1159/000501043

[8] Cremonini, C., Lewis, M., Wong, M.D., Benjamin, E.R., Inaba, K. and Demetriades, D. (2020) Traumatic Epidural Hematomas in the Pediatric Population: Clinical Characteristics and Diagnostic Pitfalls. Journal of Pediatric Surgery, 55, 1773-1778. https://doi.org/10.1016/j.jpedsurg.2020.05.011

[9] Maggi, G., Aliberti, F., Petrone, G. and Ruggiero, C. (1998) Extradural Hematomas in Children. Journal of Neurosurgical Sciences, 42, 95-99.

[10] Spazzapan, P., Krašovec, K. and Velnar, T. (2019) Risk Factors for Bad Outcome in Pediatric Epidural Hematomas: A Systemic Review. Chinese Neurosurgical Journal, 5, Article No. 19. https://doi.org/10.1186/s41016-019-0167-6

[11] Umerani, M.S., et al. (2018) Pediatric Extradural Hematoma: Clinical Assessment Using King's Outcome Scale for Childhood Head Injury. Asian Journal of Neurosurgery, 13, 681-684.

[12] Jung, S.W. and Kim, D.W. (2012) Our Experience with Surgically Treated Epidural Hematomas in Children. Journal of Korean Neurosurgical Society, 51, 215-218. https://doi.org/10.3340/jkns.2012.51.4.215 